\title{
Current trends in candidate selection, contraindications, and indications for lung transplantation
}

\author{
Ashwini Arjuna $^{1 \#}$, Michael T. Olson ${ }^{1,2 \#}$, Rajat Walia ${ }^{1}$ \\ ${ }^{1}$ Norton Thoracic Institute, St. Joseph's Hospital and Medical Center, Phoenix, AZ, USA; ${ }^{2}$ University of Arizona College of Medicine - Phoenix, \\ Phoenix, AZ, USA \\ Contributions: (I) Conception and design: None; (II) Administrative support: None; (III) Provision of study materials or patients: None; (IV) \\ Collection and assembly of data: None; (V) Data analysis and interpretation: None; (VI) Manuscript writing: All authors; (VII) Final approval of \\ manuscript: All authors. \\ "These authors contributed equally to this work. \\ Correspondence to: Rajat Walia, MD. Norton Thoracic Institute, St. Joseph's Hospital and Medical Center, 500 W. Thomas Road, Ste. 500, Phoenix, \\ AZ 85013, USA. Email: Rajat.Walia@DignityHealth.org.
}

\begin{abstract}
Lung transplantation is an established treatment option that can improve quality of life and prolong survival for select patients diagnosed with end-stage lung disease. Given the gaps in organ donation and failures to make effective use of available organs, careful selection of candidates for lung transplant remains one of the most important considerations of the transplant community. Toward this end, we briefly reviewed recent trends in pretransplant evaluation, candidate selection, organ allocation, and organ preservation techniques. Since the latest consensus statement regarding appropriate selection of lung transplant candidates, many advances in the science and practice of lung transplantation have emerged and influenced our perspective of 'contraindications' to transplant. These advances have made it increasingly possible to pursue lung transplant in patients with risk factors for decreased survival—namely, older recipient age, increased body mass index, previous chest surgery, poorer nutritional status, and presence of chronic infection, cardiovascular disease, or extrapulmonary comorbid conditions. Therefore, we reviewed the updated evidence demonstrating the prognostic impact of these risk factors in lung transplant recipients. Lastly, we reviewed the salient evidence for current trends in disease-specific indications for lung transplantation, such as chronic obstructive pulmonary disease, idiopathic pulmonary fibrosis, cystic fibrosis, emphysema due to alpha-1 antitrypsin deficiency, and pulmonary arterial hypertension, among other less common end-stage diseases. Overall, lung transplant remains an exciting field with considerable hope for patients as they experience remarkable improvements in quality of life and survival in the modern era.
\end{abstract}

Keywords: Lung transplantation; candidate selection; contraindications; indications

Submitted Jun 03, 2020. Accepted for publication Jan 27, 2021.

doi: $10.21037 /$ jtd-2021-09

View this article at: http://dx.doi.org/10.21037/jtd-2021-09

\section{Background}

Lung transplant has been established as the treatment of choice for patients with various forms of end-stage lung disease, in whom non-transplant therapeutic options have failed. Many advances in the realms of basic science, clinical research, surgical technique, and perioperative management have emerged over the past few decades; these innovations have contributed to substantial improvements in survival and quality of life for transplant recipients. However, the field of lung transplantation faces appreciable challenges, including expanding the lung donor pool and ameliorating posttransplant complications, such as primary graft dysfunction, cellular- and antibodymediated rejection, chronic lung allograft dysfunction, and infection (1). One of the most important questions 
facing the transplant community is how to manage the gap between supply and demand of donor organs to ensure that the maximum number of potential recipients receive this life-saving intervention (2). Selecting candidates for lung transplant is predicated on the judicious guidelines established by the International Society for Heart and Lung Transplantation (ISHLT) (3). Ideal candidates for lung transplant are individuals with a terminal respiratory illness who are experiencing significant decrease in quality of life. Candidates should be able to undergo major surgery that requires prolonged recuperation and rehabilitation, and should be otherwise free of significant comorbidities that might negatively affect successful transplantation. Despite these consensus statements, many controversial issues remain regarding the selection of candidates for lung transplant. Contraindications for lung transplant are constantly evolving, as valiant investigative efforts from leading transplant institutions push the boundaries of feasibility, and indications for lung transplant also continue to expand. At the dawn of this new decade, the authors will review current trends in candidate selection, contraindications, and indications for lung transplant, describing the rationale and evidence for these trends where possible.

\section{Trends in pretransplant evaluation, candidate selection, and organ allocation}

Appropriate evaluation, selection of lung transplant candidates, and organ allocation have powerful effects on outcomes and survival after transplant (3). Currently, lung transplant centers use the following general criteria when determining an individual's potential for lung transplant: the risk of death from lung disease without transplant is $>50 \%$ within 2 years, the likelihood of surviving at least 90 days after lung transplant is $>80 \%$, and the likelihood of surviving 5 years after transplant based on analysis of comorbidities is $>80 \%$, provided that the graft functions adequately (3). However, decisions regarding referral and subsequent evaluation for lung transplant candidacy appear to be as much an art as they are a science. Decisions depend upon the waitlist, the capability and activity of the transplant center, and manifestation of the patient's underlying pathology. Every patient should be discussed with the transplant center before any definite decision is made to either accept or decline a patient for lung transplant. Additionally, an overlooked but important component of the candidate selection process is the role of the non-transplant clinician. It is critical for nontransplant clinicians to refer patients with advanced stages of lung disease earlier for lung transplant evaluation, if those patients' conditions may be amenable to transplant. Early referral may maximize patients' chances of meeting eligibility criteria for transplant, and in cases where relative contraindications are identified, patients may have an opportunity to improve such factors prior to listing (4).

Improving the management of lung transplant candidates during the pretransplant period has been the focus of much attention, as efforts to delay the time until need for transplant are being readily developed. The emergence of highly effective, targeted pharmacologic agents for diseases such as idiopathic pulmonary fibrosis (IPF), idiopathic pulmonary arterial hypertension (PAH), and cystic fibrosis (CF) have demonstrated efficacy in slowing the otherwise-rapid progressive clinical course of these respiratory illnesses (5-7). These advances in pharmacologic treatment have made later listing possible in some patients, successfully extending the time until need for transplant and contributing to an overall decrease in time-to-death for these end-stage lung diseases (8). Furthermore, chronic infections such as HIV, hepatitis B virus ( $\mathrm{HBV})$, and hepatitis $\mathrm{C}$ virus ( $\mathrm{HCV}$ ), are no longer considered insurmountable barriers to lung transplant, and recent investigations in these patients have demonstrated comparable survival to seronegative patients after transplant $(9,10)$. Novel pharmacologic therapies are demonstrating adequate infection control in these individuals, thus paving the way for more inclusive standards for transplant candidacy (11).

Furthermore, over the past 2 decades, the lung transplant community has witnessed a revolution in the allocation of donor organs thanks to the development of the lung allocation score (LAS). This system was designed to shift the distribution of donor lungs toward patients in more dire need-in other words, patients who would theoretically benefit most from transplant. After the LAS was introduced, waitlist deaths decreased significantly and the number of lung transplants increased. The LAS also resulted in double the annual number of lung transplant procedures, despite the fact that there was no increase in donors. The distribution of recipients' diagnoses also changed dramatically, with significantly more patients with fibrotic lung disease receiving transplants; the mean age of recipients increased significantly; and most patients who underwent transplant experienced a survival benefit, with the greatest benefit observed in patients with higher LAS 
scores $(12,13)$. The LAS system has been modified since it was originally introduced, and there remains a need to further refine the lung allocation process to decrease the risk of poor outcomes and associated expenses $(14,15)$.

\section{Trends in organ preservation techniques}

In the last two decades, ex vivo lung perfusion (EVLP) has emerged as a new technology with the potential to recondition human donor lungs that would otherwise fall below the acceptable threshold for transplant (16). Provided the need to expand the donor lung pool, the transplant community explored the use of EVLP as a preservation technique for suboptimal donor lungs. EVLP describes a concept of perfusing and ventilating a donor lung in an ex vivo circuit, allowing transplant clinicians an opportunity to reassess the allograft function before transplant. The feasibility of transplanting high-risk donor lungs that have undergone EVLP has been established in a few clinical trials, with results suggesting that EVLP-treated lungs share similar outcomes to conventionally selected and physiologically stable donor lungs $(17,18)$. The safety and efficacy of several EVLP techniques have been evaluated in clinical practice. Normothermic EVLP is being increasingly investigated, and while continuous normothermic EVLP is effective in rescuing organs otherwise not suitable for transplant, it has not shown to be safer or superior to cold static preservation for standard criteria donor organs. An acellular EVLP technique has also been developed with the capability of maintaining donor lungs for at least 12 hours at body temperature without inducing allograft injury (19). Existing studies are actively evaluating the potential for EVLP to improve the function of lung allografts already deemed acceptable for transplant (20). Ultimately, EVLP remains a promising technique to increase the number of higher-quality human donor lungs, and future research may yield it feasible to integrate other pharmacologic and gene or cellular therapies with treatment.

\section{Trends in relative contraindications}

The selection of appropriate lung transplant candidates is a multifactorial decision that begins with identifying patients' contraindications to the procedure. The aforementioned recipient selection guidelines were developed to supply transplant clinicians with the most robust scientific evidence available for suitable candidates. Since the development of these guidelines, transplant centers have carefully weighed this evidence with the goal of safely providing therapy to as many patients as possible, including those diagnosed with complex medical conditions. Because centers have begun routinely transplanting patients with relative contraindications identified within these consensus statements, a discussion of the most recent guidelines is warranted. Especially controversial relative contraindications will be reviewed below, in light of since-published evidence regarding patients with existing comorbidities undergoing transplant.

\section{Recipient age}

Existing recommendations state that age alone should not be considered a contraindication to transplant, with the caveat that patients over 75 years of age are unlikely to be candidates. Recipient age over 65 years, if associated with low physiologic reserve and/or other relative contraindications, should remain a relative contraindication to transplant (3). Despite this recommendation, it has become increasingly common over the past decade to perform lung transplant in patients older than 65 years; the most recent investigations have detailed the clinical outcomes of these patients from a national registry $(21,22)$. These studies have revealed acceptable outcomes in wellselected end-stage lung disease patients over the age of 65 years, and these appear comparable to outcomes in younger recipients. Recipients aged 70 years and older have made up a greater proportion of the overall lung transplant population after implementation of the LAS, and studies have revealed acceptable clinical outcomes and early survival rates in this cohort (23-25). The results of future clinical series investigating the age-old question of whether advanced age is reason to withhold life-prolonging treatment in patients with otherwise-acceptable risk profiles are eagerly anticipated.

\section{Nutritional status}

The nutritional status of lung transplant candidates is related to posttransplant survival (26); therefore, guidelines state that class I obesity [i.e., body mass index (BMI) $30.0-34.9 \mathrm{~kg} / \mathrm{m}^{2}$ ], particularly truncal (central) obesity, is a relative contraindication to lung transplant, whereas classes II and III obesity (BMI $>35.0-39.9 \mathrm{~kg} / \mathrm{m}^{2}$ and BMI $\geq 40.0 \mathrm{~kg} / \mathrm{m}^{2}$ ) are listed as absolute contraindications (3). Malnourishment is also cause for great concern in potential lung transplant candidates, especially in those with CF 
and chronic obstructive pulmonary disease (COPD), and improved nutritional status must be aggressively pursued before listing (27-29). The basis for pretransplant obesity as a contraindication is founded in multiple studies demonstrating significant risk for mortality after lung transplant in overweight and obese recipients, independent of other risk factors (27,30-33). However, a subsequent study in the LAS era found no significant associations between class I obesity and short-term mortality after lung transplant; importantly, classes II and III obesity were associated with a nearly twofold increase in mortality (34). Despite its appearance on recipient selection guidelines, a BMI greater than or equal to $30 \mathrm{~kg} / \mathrm{m}^{2}$ may not preclude lung transplant, and the decision to perform a transplant procedure in patients with class I obesity remains the responsibility of individual centers.

Furthermore, the validity of BMI as a measure of obesity has been questioned, mainly relating to its inability to distinguish body composition types, resulting in errors in classification (35). Alternative methods of measuring obesity, such as adipose tissue quantification, are apt at identifying volumes of subcutaneous and visceral adipose tissue using software-based assessments of computed tomograms of the thorax, and may provide more valuable insight into patients' body habitus (36). Biomarkers, including leptin, interleukin receptor 1 antagonist, and intercellular adhesion molecule 1 levels, are associated with adipose tissue volumes and offer stronger predictions for risk of primary graft dysfunction after transplant (37).

\section{Osteoporosis}

Severe, symptomatic osteoporosis is considered a relative contraindication to lung transplant (3). Osteoporosis is common in patients before and after transplant; both the endorgan failure before transplant, and the immunosuppression regimens implemented posttransplant contribute to reduction in bone mass, quality, and strength (38). Bone loss is especially common in the early posttransplant period, often a complication of glucocorticoid administration, and the goal should be to use the lowest possible dose and to taper and withdraw glucocorticoids as early as possible (38). All transplant candidates should be monitored for osteoporosis and fracture risk, and when indicated, therapy should be initiated early before transplant (39). Patients with CF awaiting lung transplant for end-stage respiratory failure are particularly at risk of developing bone disease and fragility fracture, given their suboptimal levels of 25-hydroxyvitamin
D levels (40). With appropriate screening and treatment early before transplant, severe, symptomatic osteoporosis may not contraindicate lung transplant.

\section{Prior chest surgery}

Extensive prior cardiothoracic surgical procedures and those requiring lung resection may increase both the technical difficulty of explanting the native lung and the operative risk of lung transplant. Therefore, extensive prior chest surgery is stated as a relative contraindication to lung transplant in consensus guidelines (3). Nonetheless, patients who have undergone prior surgical procedures of the chest [e.g., a coronary artery bypass graft (CABG)] are increasingly undergoing lung transplant in recent years. Whether it should remain a contraindication is debated, as reports of its impact on survival after lung transplant are conflicting in the literature. In a series of 14,791 patients who underwent transplant between 2004 and 2013, 292 (2\%) had previously undergone a CABG, which was a predictor of mortality at 1,3 , and 5 years, with an overall hazard ratio of 1.97 (95\% CI, 1.23-3) (41). However, the effect was largely due to increased mortality among those who underwent bilateral lung transplant (BLT). In a more recent series of 333 patients who underwent lung transplant between 2004 and 2013, no association was seen between 3-way coronary artery disease (CAD) status (CAD-CABG, CAD-No CABG, No CAD) and overall re-transplant-free survival after adjusting for age, gender, and transplant indication (42). Simple pneumothorax treated by closed tube thoracostomy, open lung biopsy, or uncomplicated lobectomy should not preclude patients to lung transplant, and more complex cases, such as patients who have undergone CABG, may undergo lung transplant at the discretion of the center. In the current era, prior cardiothoracic procedures are no longer considered contraindications to lung transplant (43).

\section{Extracorporeal life support}

It is not uncommon for lung transplant candidates with end-stage lung disease to decompensate acutely before a donor organ becomes available. In this scenario, extracorporeal life support (ECLS) may be considered as a bridge to transplant or as a bridge to decision (44). Historically, mechanical ventilation and/or ECLS were included as a relative contraindication to transplant on recipient selection guidelines, although it is stated that select candidates without other acute or chronic 
organ dysfunction may be successfully transplanted (3). However, advances in ECLS technology, personnel training, and lung-protective strategies have improved outcomes in patients who have received bridge therapy to lung transplant (45), and in the past several years, ECLS use has gradually increased for patients with severe respiratory failure (46). Notably, the use of ECLS increased 200\% between 2009 and 2013 (47). When applied to patients whose pulmonary function has rapidly declined, long-term outcomes and functional status after transplant have been reported to be comparable to those who did not receive ECLS as a bridge to transplant (48). A recent stratified outcome analysis amassing 20 years of institutional experience with ECLS also revealed that ECLS bridging yielded similar long-term survival compared with non-bridged patients (49). There are no universally accepted indications for ECLS bridge to transplant, but factors such as age, functional status, disease process, infection, other organ failure, and anticipated time on the waitlist are considered when determining a patient's benefit from this therapy (50). Contraindications for ECLS are also based on institutional experience, although traditional contraindications for lung transplant may likewise be considered contraindications for $\operatorname{ECLS}(3,50)$. The practice of ECLS is actively evolving, as experiences with ambulatory ECLS are being reported (51,52). Ambulatory ECLS may help prevent deconditioning in patients awaiting organs and subsequent transplant, and further research may elicit additional advantages $(53,54)$.

\section{Colonization and infection}

Colonization or infection with highly resistant or highly virulent bacteria, fungi, and certain strains of mycobacteria (e.g., chronic extrapulmonary infection expected to worsen after transplant) is considered a relative contraindication to lung transplant and significantly influences decisions on whether transplant is an appropriate treatment option (3). Colonization and chronic infection are especially common in patients with bronchiectasis and CF, and strains of Aspergillus species, Burkholderia cenocepacia, Burkbolderia gladioli, and nontuberculous mycobacteria are frequently cultured in sputum samples from these patients $(55,56)$. Patients referred for lung transplant evaluation are assessed for infection by these microorganisms, and some centers with less experience in managing infection may decline the patient for transplant. In high-volume and experienced centers, the patient is considered for transplant if there is reasonable expectation that antibiotic or antifungal therapy will adequately control the infection. In cases of rapidly progressive infection with pan-resistant bacterial strains before or after transplant, targeted combination antibiotic therapy is indicated for eradication $(57,58)$. Bacteriophage therapy is a novel strategy for treatment of multi-drug-resistant bacterial infections; its use has been reported in 3 transplant recipients diagnosed with lifethreatening multi-drug-resistant Pseudomonas aeruginosa or Burkholderia dolosa infections (59). Bacteriophage therapy necessitates further investigation, but initial experiences have demonstrated promising results for the treatment of multi-drug-resistant infections unresponsive to antibiotic therapy alone. Likewise, chronic infection combined with HIV, HBV, and HCV were recently considered relative contraindications to lung transplant (3). However, studies have since demonstrated that lung transplant may be acceptable for patients whose chronic infection is adequately managed $(9,10,60)$. Appropriate management of HIV may be evidenced by undetectable HIV-RNA, lack of AIDS-defining opportunistic illnesses, and demonstrated adherence to combination antiretroviral therapy. Acceptable candidates with chronic HBV or HCV infection are stable on appropriate therapy and should demonstrate no significant clinical, radiological, or biochemical evidence of portal hypertension or cirrhosis. Direct-acting antiviral therapy in patients with $\mathrm{HCV}$ may even have curative results in patients undergoing lung transplant (61). Overall, patients with the above-mentioned infections are more commonly being considered suitable transplant candidates, despite existing guidelines, when these patients are evaluated at transplant centers with significant experience in managing these infections in the transplant setting.

Within the scope of infection, it is certainly necessary to discuss the lasting impact of the coronavirus disease 2019 (COVID-19) pandemic on the lung transplant community, and moreover, the optimal selection and care of donor lungs. Reports describing the virology, clinical manifestations, diagnosis, and management of COVID-19 have saturated the literature in the past year, yet there is still much to determine-namely, its effect on the safety of elective (and transplant) surgeries (62), whether transmission of the virus from donor to recipient via a lung allograft is plausible, and how infection influences the progression of allograft rejection. Most recently, Bharat et al. (63) shared their honorable efforts to successfully transplant three patients suffering from non-resolving COVID-19-associated respiratory failure. Meanwhile, 
Ceulemans et al. (64) were among the first to successfully perform a lung transplant from a donor with confirmed, mild COVID-19 symptoms three months prior to donation. These early reports certainly demonstrate a resilience amongst our transplant community, lung donors, and lung transplant candidates and recipients. In sum, evidence regarding COVID-19 in lung transplantation is constantly evolving, and we have made considerable progress since the beginning of the pandemic; another article in this series will cover COVID-19 and lung transplantation in detail.

\section{Coronary artery disease}

Atherosclerotic disease burden without end-organ dysfunction is considered a relative contraindication to lung transplant in consensus guidelines (3). However, several single-center studies have shown that posttransplant outcomes in patients with CAD are comparable to those without CAD when adequately palliated with coronary revascularization $(65,66)$. There is variability in institutional practice policies with respect to evaluating and managing $\mathrm{CAD}$ in patients with end-stage lung disease who have been referred for lung transplant, as well as when to safely list patients with CAD who are undergoing coronary intervention for severe coronary disease. Selection of the mode of coronary intervention (i.e., bare metal stent $v s$. drugeluting stent vs. CABG) based on CAD severity has also been debated in literature $(67,68)$. Nonetheless, satisfactory outcomes have been well documented in patients with coronary artery disease who undergo lung transplant, and importantly, these recipients rarely die of cardiac causes (69). Because the risk imposed by coronary artery disease can be adequately minimized in transplant candidates who undergo effective palliation, lung transplant should be seriously considered in patients with atherosclerotic disease burden without end-organ dysfunction. Additional study on the prognostic impact of other pretransplant cardiovascular abnormalities, such autonomic dysfunction (70), will also better inform our community.

\section{Extrapulmonary conditions}

Lastly, consensus guidelines state that certain extrapulmonary conditions that have not resulted in end-stage organ damage, including diabetes mellitus, systemic arterial hypertension, epilepsy, central venous obstruction, peptic ulcer disease, or gastroesophageal reflux, should be optimally treated before pursuing lung transplant (3). The above-mentioned comorbid diseases have been purported to increase the likelihood of complications before or after the transplant procedure, and may therefore adversely impact the short- and long-term prognoses of the transplant (71). As with all relative contraindications, it is critical for the referring agency and the transplant center to establish effective communication to facilitate early detection of any comorbidity, as this gives the potential transplant candidate the greatest amount of time to reduce the risks associated with their concurrent medical condition.

\section{Trends in absolute contraindications}

A number of absolute contraindications to lung transplant were also listed in the most recent recipient selection guidelines, with similar intentions of establishing criteria that optimize the likelihood of survival for patients after transplant (3). Absolute contraindications are largely considered inviolable in the process of evaluating a patient referred for lung transplant; therefore, evidence for each of these determinations will not be included in this review. However, a few studies have examined outcomes after lung transplant in recipients with less than a 2- or 5-year diseasefree interval, as indicated, from malignancy. Salient records of the current trends in lung transplant for patients with a history of malignancy will be reviewed.

\section{Malignancy}

Current guidelines suggest that lung transplant should not be offered to adults who have a recent history of malignancy (3), as malignancies are more common and may behave more aggressively in immunosuppressed transplant recipients $(72,73)$. A 2-year disease-free interval combined with a low predicted risk of recurrence after lung transplant may be reasonable, such as in the case of skin cancers other than melanoma that have been treated appropriately. Localized non-melanoma skin cancer is generally not considered a contraindication to lung transplant, but remains common in the posttransplant period (74). A 5 -year disease-free interval should be demonstrated in most cases, particularly for those with a history of hematologic malignancy, sarcoma, melanoma, or cancers of the breast, bladder, or kidney. Unfortunately, for certain types of cancer (e.g., bronchial carcinoma), the risk of recurrence may remain too high to proceed with lung transplant, even after a 5 -year disease-free interval (75).

One malignancy that may contradict these guidelines is 
localized prostate cancer. Many low-risk prostate cancers may only require active surveillance, thus whether this cancer should negate lung transplant candidacy is debated. Endstage lung disease patients with low-risk prostate cancer may still benefit from lung transplant, as it may both improve quality of life and increase life expectancy. In the largest clinical series available, 4 patients with prostate cancer were safely listed without the recommended 2-year cancer-free period, and had acceptable short-term survival following transplant without receiving curative treatment (76). Nevertheless, data remain scarce, and future studies reporting recurrence-free survival after lung transplant in patients with prostate cancer diagnosed during evaluation are necessary to substantiate this practice.

\section{Trends in disease-specific indications}

Lung transplant has been performed worldwide, with increasing annual numbers (77). According to data from the International Thoracic Organ Transplant Registry (2019), the most common indications for lung transplant are advanced COPD (30.1\%), idiopathic interstitial pneumonia (IIP) $(26.1 \%)$, CF (15.2\%), non-IIP interstitial lung disease (ILD) $(5.7 \%)$, emphysema due to alpha-1 antitrypsin deficiency (A1ATD) (4.7\%), re-transplantation (4.0\%), and idiopathic PAH (2.9\%) (77). These conditions account for nearly $90 \%$ of all lung transplant procedures, while the remaining $10 \%$ is attributed to a variety of diagnoses that span the spectrum of end-stage lung disease, including nonCF bronchiectasis, sarcoidosis, lymphangioleiomyomatosis, connective tissue disease, and pulmonary Langerhans cell histiocytosis. Current trends show that ILD (IIP and nonIIP) as a primary diagnosis comprises the largest percentage of patients (31.8\%) undergoing lung transplant.

The most recent registry data (77) stratify survival outcomes by transplantation era: 1992-2001, 2002-2009, and 2009-2016. Overall median survival in the most recent era (i.e., 2009-2016) is 6.7 years, compared to 6.5 years and 4.7 years in 2002-2009 and 1992-2001, respectively. The median survival rate according to underlying pulmonary disease differs markedly; patients with $\mathrm{CF}$ as an indication for lung transplant have superior survival (median 9.9 years) compared to all other groups. Below, the current trends in disease-specific indications will be reviewed, including any changes in practice.

\section{Idiopathic pulmonary fibrosis}

Idiopathic pulmonary fibrosis is the most common ILD among referrals for lung transplant, as well as the most frequent disease for which lung transplant is performed (77). Timing for referral is based on clinicians' confident radiographic diagnosis of IPF, or a histologic diagnosis of IPF or fibrosing nonspecific interstitial pneumonia, regardless of lung function (3). Patients with ILD, specifically IPF, have the worst prognosis and highest death rates on the waitlist among the common disease indications for lung transplant (78). However, since the inception of the LAS, transplant and mortality rates for patients with IPF have substantially improved (79). IPF is common among elderly transplant candidates, and in the LAS era, an increased number of organs are being allocated to patients with IPF who are older than 65 years (22). Nonetheless, it remains difficult to predict which IPF patients have the highest risk for mortality; therefore, the ISHLT recently proposed updated referral and listing guidelines based on available prognostic indicators in IPF (3).

Management of IPF is evolving rapidly in clinical practice. Recent ATS/ERS/JRS/ALAT Clinical Practice Guidelines conditionally recommended that patients be managed with antifibrotic agents (e.g., pirfenidone) throughout the referral and evaluation process (80). Previous combinations of prednisone, azathioprine, and $\mathrm{N}$-acetylcysteine have been associated with increased risk for hospitalization and death compared to placebo treatments in patients with IPF (81). Three multinational, randomized, placebo-controlled phase III trials have since shown that pirfenidone can reduce the rate of IPF progression by $50 \%$ on average in a single year, measured by serial changes in forced vital capacity (82). A survival benefit in patients with IPF who undergo treatment with pirfenidone is also well documented $(83,84)$.

Once a patient with IPF is listed for lung transplant, the most important goal becomes maintaining their functional status. History of $\mathrm{CAD}$ at the time of listing and $\mathrm{PCO}_{2}$ and mechanical support at the time of transplant are predictive factors of posttransplant survival (85); therefore, these patients should participate in pulmonary rehabilitation programs before undergoing transplant (86). Although single-lung transplant (SLT) has historically been the standard of practice for IPF $(87,88)$, several investigations have since demonstrated the benefit of BLT on long-term survival $(89,90)$.

New evidence elicited from basic science research has emerged in the past few years, and it has redefined our understanding of IPF pathogenesis and considerations after treatment. Wu et al. (91) identified a novel contribution 
to IPF pathogenesis through the loss of Cdc42 function in alveolar stem cells (AT2 cells), which leads to the peripheryto-center pattern of progressive lung fibrosis. Elevated mechanical tension also activates a TGF- $\beta$ signaling loop in AT2 cells, driving this progression. Furthermore, mutations in the telomerase complex (e.g., TERT and TR), which serve to maintain telomere length, have now been associated with IPF and hematologic disorders such as myelodysplasia, and so these mutations may place patients at risk for adverse hematologic outcomes and complications after lung transplant $(92,93)$. The development of specific recommendations for hematologic risk assessment before transplant is anticipated.

\section{Chronic obstructive pulmonary disease}

Chronic obstructive pulmonary disease (non-A1ATD and A1ATD) constitutes one of the most common indications for lung transplant worldwide (77). In current practice, the exact determination of when to refer, list, and offer lung transplant is still equivocal. The most recent ISHLT recommendations suggest that patients with COPD should be referred for lung transplant when their condition continually progresses despite smoking cessation, optimization of medications, pulmonary rehabilitation, and supplemental oxygen (3). Additional referral criteria include a BODE index of 5 to $6, \mathrm{PCO}_{2}>50 \mathrm{mmHg}(6.6 \mathrm{kPa})$ and/ or $\mathrm{PO}_{2}<60 \mathrm{mmHg}(8 \mathrm{kPa})$, or forced expiratory volume in one second $\left(\mathrm{FEV}_{1}\right)<25$ percent of predicted (3). Defining disease severity and urgency for transplant can also be quite complex. Therefore, the following criteria have been suggested as necessitating transplant; the presence of one of these conditions is sufficient for listing: BODE index $\geq 7$, $\mathrm{FEV}_{1}<15 \%$ to $20 \%$ of predicted, $\geq 3$ severe exacerbations in the past year, 1 severe exacerbation with acute hypercapnic respiratory failure, or moderate to severe PAH (3). These thresholds, particularly for the BODE index, are based on a study of 54 patients at 2 Swiss hospitals that demonstrated improved median survival after transplant in a subgroup of patients with BODE index $\geq 7$ (94). Posttransplant survival is superior in patients with COPD compared with patients diagnosed with most other end-stage lung diseases [median 7.1 years (A1ATD)], with the greatest benefit observed in patients with more advanced stages of disease $(77,94)$.

Single lung transplant was once considered the procedure of choice for patients with COPD after management of the allograft was improved and the ventilation and perfusion mismatch was minimized (95). In preceding decades leading up to the modern day, the BLT has gradually become the predominant surgical approach for patients with a primary diagnosis of COPD (77). Initial retrospective studies investigating survival benefit by procedural type favored BLT over SLT, especially for younger recipients with COPD $(96,97)$. Subsequent analysis of the ISHLT/United Network of Organ Sharing databases revealed a survival benefit for patients younger than 60 years receiving BLT; however, the benefit ceased in older recipients, as mortality after BLT increased in this demographic (98). A more recent analysis performed in the LAS era found no difference in survival at 5 years when comparing patients with COPD who received either SLT or BLT (99). The authors, however, noted that survival would likely favor BLT if the analysis were extended to 10 years, and perhaps equally importantly, BLT was associated with better allograft survival. Ongoing studies are needed to determine the ideal timing and type of transplant for patients with COPD.

\section{Cystic fibrosis}

Although lung transplant was not initially offered to patients with CF on account of the higher incidence of infectious complications in this subgroup, it is now one of the more common indications for lung transplant (77). The appropriate referral criteria were originally detailed by the ISHLT (3), and in 2019 the Cystic Fibrosis Foundation provided updated recommendations on the appropriate, timely referral of patients with CF (100). Importantly, these guidelines emphasize the significance of early discussion of lung transplant as a treatment option, assessment for modifiable barriers to transplant, and establishing communication between the referring and transplant centers. Since lung transplant became a viable option for patients with $\mathrm{CF}$, these transplant recipients have observed superior survival rates compared to all other indications for lung transplant (77).

Nevertheless, colonization and infectious complications with multi-drug-resistant bacteria remain a challenge for patients with CF (55). All patients with CF who are referred for transplant are to be evaluated for the presence of $B$ cenocepacia; patients with species other than $B$ cenocepacia do not constitute an increased risk for mortality after transplant, and they can be listed provided that other criteria are met (75). However, it is recommended that centers accepting such patients have an active research program assessing novel approaches to preventing and 
controlling recurrent disease, and these centers should ultimately be experienced in managing these patients (75).

At the advent of cystic fibrosis transmembrane conductance regular (CFTR) modulation as a targeted, pharmacologic therapy, the clinical management of CF has seen dramatic changes in just the past few years. The FDA approval of ivacaftor, as well as the subsequent development of dual combination therapies, significantly influenced the disease course for patients diagnosed with $\mathrm{CF}$, and has contributed to improvements in survival rates (101). Dual therapies have since opened the door for triple-combination, CFTR modulation therapy currently in clinical trials. Near the end of this year, Middleton et al (102), with support of the VX17-445-102 Study Group, reported the results of a phase III, randomized, double-blind, placebo-controlled trial confirming the efficacy and safety of a triple treatment with elexacaftor/tezacaftor/ivacaftor in patients diagnosed with CF who had Phe508del-minimal function genotypes. They found sustained improvements in $\mathrm{FEV}_{1}$ and sweat chloride concentrations, with a reduction in the number of pulmonary exacerbations in patients for whom previous treatment with other CFTR modulator regimens failed. Future research is being directed toward offering modulation therapy for the majority of CF genotypes. Although their impact on lung transplant is yet to be identified, these advancements in targeted pharmacologic therapy may have promising effects on delaying the progression of $\mathrm{CF}$ and the time to transplant.

\section{Pulmonary arterial hypertension}

Pulmonary arterial hypertension, and more specifically idiopathic PAH (IPAH), is a valid but rare indication for lung transplant in the current age (77). Judging the appropriate timing and making the decision to refer patients with pulmonary vascular disease for transplant evaluation may be challenging for clinicians, despite existing guidelines (3). The decision to refer, list, and perform transplant in patients with IPAH is complicated by the development of targeted medical therapies that have improved IPAH management. Medical therapies, including prostanoids, endothelin receptor antagonists, and phosphodiesterase inhibitors, are efficacious in managing IPAH; therefore, most patients who would have been listed for transplant in the pre-prostanoid era may not require transplant listing while awaiting clinical response to medical therapy (75). In patients with medically refractory IPAH in whom transplant is deemed suitable, BLT or heart-lung transplant are the surgical procedures of choice, and they are considered a definitive therapy $(103,104)$. However, transplant is not necessarily associated with improved survival; the 3-year survival of patients who underwent lung or heart-lung transplant for IPAH is approximately $50 \%$ (77). Notably, the incidence of bronchiolitis obliterans syndrome (BOS) appears to be higher in patients with IPAH who undergo lung transplant (105), although this finding warrants more investigation. Recurrence rates of IPAH after transplant have not been reported.

\section{Diffuse parenchymal lung disease}

Diffuse parenchymal lung disease (DPLD) constitutes a minority of all indications for lung transplant, with IPF being the largest indication amongst all DPLD (77). The other DPLD for which transplants are performed include sarcoidosis, lymphangioleiomyomatosis, connective tissue disease, pulmonary Langerhans cell histiocytosis, and collagen vascular disease-associated ILDs, such as systemic sclerosis (scleroderma), polymyositis, and rheumatoid arthritis (106).

\section{Scleroderma and gastroesophageal reflux disease}

Lung transplant may be an appropriate therapeutic option for carefully selected scleroderma patients with severe ILD or pulmonary hypertension that remains unresponsive to pharmacologic treatment (107). However, the presence of extrapulmonary manifestations of scleroderma (e.g., esophageal, renal, or cardiac disease) should be assessed and managed accordingly. Esophageal dysmotility and gastroesophageal reflux disease (GERD) require especially careful evaluation, considering the progressive nature of GERD after lung transplant (108). In a recent clinical series of patients with scleroderma who underwent lung transplant, including those with gross reflux and esophageal dysfunction, survival at 5 years was $70 \%$. Moreover, the prevalence of BOS in these patients was comparable to the prevalence in patients without scleroderma (109). GERD is thought to play a significant role in the decline in lung function before transplant, as well as in allograft dysfunction after lung transplant, especially acute rejection and BOS (110-112). Treatment for GERD in transplant recipients may necessitate surgical intervention, such as a Nissen fundoplication. We have previously validated the importance of performing a fundoplication early (within 6 months) after lung transplant, as it may protect against 
GERD-induced lung damage in lung transplant recipients with GERD (113). We also demonstrated the ability of an early fundoplication to slow the decline of pulmonary function posttransplant, measured by a slower decline in $\mathrm{FEV}_{1}$. However, the impact of early surgical intervention for GERD on the occurrence of BOS requires further investigation (114-116).

\section{Conclusions}

Appropriate selection of candidates for lung transplant is not an exact science, and decisions regarding listing may rely heavier on newer evidence and the experience of the transplant center, rather than the most recent international guidelines for recipient selection. In general, nontransplant clinicians should understand the importance of referring patients with end-stage lung disease earlier for transplant evaluation, as patients' existing contraindications may be modifiable. At the dawn of the next decade, lung transplantation remains an exciting field with considerable hope for patients as they experience momentous improvements in quality of life and survival.

\section{Acknowledgments}

Funding: None.

\section{Footnote}

Provenance and Peer Review: This article was commissioned by the Guest Editor (Jonathan D'Cunha) for the series "Lung Transplantation: Past, Present, and Future" published in Fournal of Thoracic Disease. The article has undergone external peer review.

Conflicts of Interest: All authors have completed the ICMJE uniform disclosure form (available at http:// dx.doi.org/10.21037/jtd-2021-09). The series "Lung Transplantation: Past, Present, and Future" was commissioned by the editorial office without any funding or sponsorship. All authors have no other conflicts of interest to declare.

Ethical Statement: All authors are accountable for all aspects of the work in ensuring that questions related to the accuracy or integrity of any part of the work are appropriately investigated and resolved.

Open Access Statement: This is an Open Access article distributed in accordance with the Creative Commons Attribution-NonCommercial-NoDerivs 4.0 International License (CC BY-NC-ND 4.0), which permits the noncommercial replication and distribution of the article with the strict proviso that no changes or edits are made and the original work is properly cited (including links to both the formal publication through the relevant DOI and the license). See: https://creativecommons.org/licenses/by-nc-nd/4.0/.

\section{References}

1. Meyer KC. Recent advances in lung transplantation. F1000Res 2018;7:F1000 Faculty Rev-1684.

2. Courtwright A, Cantu E. Evaluation and Management of the Potential Lung Donor. Clin Chest Med 2017;38:751-9.

3. Weill D, Benden C, Corris PA, et al. A consensus document for the selection of lung transplant candidates: 2014--an update from the Pulmonary Transplantation Council of the International Society for Heart and Lung Transplantation. J Heart Lung Transplant 2015;34:1-15.

4. Young KA, Dilling DF. The Future of Lung Transplantation. Chest 2019;155:465-73.

5. Varone F, Inoue Y, Richeldi L. Twenty-five years of Respirology: Advances in idiopathic pulmonary fibrosis. Respirology 2020;25:20-2.

6. Mall MA, Mayer-Hamblett N, Rowe SM. Cystic Fibrosis: Emergence of Highly Effective Targeted Therapeutics and Potential Clinical Implications. Am J Respir Crit Care Med 2020;201:1193-208.

7. Taichman DB, Ornelas J, Chung L, et al. Pharmacologic therapy for pulmonary arterial hypertension in adults: CHEST guideline and expert panel report. Chest 2014;146:449-75.

8. Hook JL, Lederer DJ. Selecting lung transplant candidates: where do current guidelines fall short? Expert Rev Respir Med 2012;6:51-61.

9. Koval CE, Farr M, Krisl J, et al. Heart or lung transplant outcomes in HIV-infected recipients. J Heart Lung Transplant 2019;38:1296-305.

10. Cypel M, Feld JJ, Galasso M, et al. Prevention of viral transmission during lung transplantation with hepatitis C-viraemic donors: an open-label, single-centre, pilot trial. Lancet Respir Med 2020;8:192-201.

11. George MP. Time to reconsider transplant criteria for candidacy? Lung transplantation feasibility in HIVinfected patients. Ann Am Thorac Soc 2014;11:962-3.

12. Egan TM, Edwards LB. Effect of the lung allocation score 
on lung transplantation in the United States. J Heart Lung Transplant 2016;35:433-9.

13. Vock DM, Durheim MT, Tsuang WM, et al. Survival Benefit of Lung Transplantation in the Modern Era of Lung Allocation. Ann Am Thorac Soc 2017;14:172-81.

14. Colvin-Adams M, Valapour M, Hertz M, et al. Lung and heart allocation in the United States. Am J Transplant 2012;12:3213-34.

15. Elnahas S, Roy SB, Olson MT, et al. Inpatient Lung Transplant Evaluation is Associated With Increased Risk of Morbidity, Mortality, and Cost of Care After Transplant. Chest 2018;154:1108A-9A.

16. D'Cunha HC, Rojas M. Ex Vivo Lung Perfusion: Past, Present, and Future. ASAIO J 2018;64:135-9.

17. Cypel M, Yeung JC, Liu M, et al. Normothermic ex vivo lung perfusion in clinical lung transplantation. N Engl J Med 2011;364:1431-40.

18. Cypel M, Yeung JC, Machuca T, et al. Experience with the first 50 ex vivo lung perfusions in clinical transplantation. J Thorac Cardiovasc Surg 2012;144:1200-6.

19. Cypel M, Yeung JC, Hirayama S, et al. Technique for prolonged normothermic ex vivo lung perfusion. J Heart Lung Transplant 2008;27:1319-25.

20. Slama A, Schillab L, Barta M, et al. Standard donor lung procurement with normothermic ex vivo lung perfusion: A prospective randomized clinical trial. J Heart Lung Transplant 2017;36:744-53.

21. Biswas Roy S, Alarcon D, Walia R, et al. Is There an Age Limit to Lung Transplantation? Ann Thorac Surg 2015;100:443-51.

22. Hayanga AJ, Aboagye JK, Hayanga HE, et al. Contemporary analysis of early outcomes after lung transplantation in the elderly using a national registry. $\mathrm{J}$ Heart Lung Transplant 2015;34:182-8.

23. Kilic A, Merlo CA, Conte JV, et al. Lung transplantation in patients 70 years old or older: have outcomes changed after implementation of the lung allocation score? J Thorac Cardiovasc Surg 2012;144:1133-8.

24. Elnahas S, Kang P, Roy SB, et al. Outcomes of Lung Transplant Recipients 70 and Over. J Heart Lung Transplant 2019;38:S335.

25. Olson MT, Arjuna A, Roy SB, et al. Outcomes of lung transplant recipients 75 years and older: A single-center experience. Chest 2020;158:A2394.

26. Jomphe V, Lands LC, Mailhot G. Nutritional Requirements of Lung Transplant Recipients: Challenges and Considerations. Nutrients 2018;10:790.

27. Lederer DJ, Wilt JS, D'Ovidio F, et al. Obesity and underweight are associated with an increased risk of death after lung transplantation. Am J Respir Crit Care Med 2009;180:887-95.

28. Snell GI, Bennetts K, Bartolo J, et al. Body mass index as a predictor of survival in adults with cystic fibrosis referred for lung transplantation. J Heart Lung Transplant 1998; 17:1097-103.

29. Landbo C, Prescott E, Lange P, et al. Prognostic value of nutritional status in chronic obstructive pulmonary disease. Am J Respir Crit Care Med 1999;160:1856-61.

30. Madill J, Gutierrez C, Grossman J, et al. Nutritional assessment of the lung transplant patient: body mass index as a predictor of 90-day mortality following transplantation. J Heart Lung Transplant 2001;20:288-96.

31. Kanasky WF, Anton SD, Rodrigue JR, et al. Impact of body weight on long-term survival after lung transplantation. Chest 2002;121:401-6.

32. Allen JG, Arnaoutakis GJ, Weiss ES, et al. The impact of recipient body mass index on survival after lung transplantation. J Heart Lung Transplant 2010;29:1026-33.

33. Gries CJ, Bhadriraju S, Edelman JD, et al. Obese patients with idiopathic pulmonary fibrosis have a higher 90-day mortality risk with bilateral lung transplantation. J Heart Lung Transplant 2015;34:241-6.

34. Singer JP, Peterson ER, Snyder ME, et al. Body composition and mortality after adult lung transplantation in the United States. Am J Respir Crit Care Med 2014;190:1012-21.

35. Lederer DJ, Kawut SM, Wickersham N, et al. Obesity and primary graft dysfunction after lung transplantation: the Lung Transplant Outcomes Group Obesity Study. Am J Respir Crit Care Med 2011;184:1055-61.

36. Halloran K, Snell GI. Adipose tissue characterization and primary lung graft dysfunction. J Heart Lung Transplant 2019;38:1257-8.

37. Hamilton BCS, Kukreja J, Ware LB, et al. Protein biomarkers associated with primary graft dysfunction following lung transplantation. Am J Physiol Lung Cell Mol Physiol 2017;312:L531-41.

38. Anastasilakis AD, Tsourdi E, Makras P, et al. Bone disease following solid organ transplantation: A narrative review and recommendations for management from The European Calcified Tissue Society. Bone 2019;127:401-18.

39. Starr SP. Immunology Update: Long-Term Care of Solid Organ Transplant Recipients. FP Essent 2016;450:22-7.

40. Cairoli E, Eller-Vainicher C, Morlacchi LC, et al. Bone involvement in young adults with cystic fibrosis awaiting lung transplantation for end-stage respiratory failure. 
Osteoporos Int 2019;30:1255-63.

41. McKellar SH, Bowen ME, Baird BC, et al. Lung transplantation following coronary artery bypass surgeryimproved outcomes following single-lung transplant. J Heart Lung Transplant 2016;35:1289-94.

42. Halloran K, Hirji A, Li D, et al. Coronary Artery Disease and Coronary Artery Bypass Grafting at the Time of Lung Transplantation Do Not Impact Overall Survival. Transplantation 2019;103:2190-5.

43. Omara M, Okamoto T, Arafat A, et al. Lung transplantation in patients who have undergone prior cardiothoracic procedures. J Heart Lung Transplant 2016;35:1462-70.

44. Loor G, Simpson L, Parulekar A. Bridging to lung transplantation with extracorporeal circulatory support: when or when not? J Thorac Dis 2017;9:3352-61.

45. Salna M, Bacchetta M. Extracorporeal lung support. Curr Opin Anaesthesiol 2017;30:50-7.

46. Sharma NS, Hartwig MG, Hayes D. Extracorporeal membrane oxygenation in the pre and post lung transplant period. Ann Transl Med 2017;5:74.

47. Gulack BC, Hirji SA, Hartwig MG. Bridge to lung transplantation and rescue post-transplant: the expanding role of extracorporeal membrane oxygenation. J Thorac Dis 2014;6:1070-9.

48. Todd EM, Biswas Roy S, Hashimi AS, et al. Extracorporeal membrane oxygenation as a bridge to lung transplantation: A single-center experience in the present era. J Thorac Cardiovasc Surg 2017;154:1798-809.

49. Benazzo A, Schwarz S, Frommlet F, et al. Twenty-year experience with extracorporeal life support as bridge to lung transplantation. J Thorac Cardiovasc Surg 2019;157:2515-2525.e10.

50. Toyoda Y, Bhama JK, Shigemura N, et al. Efficacy of extracorporeal membrane oxygenation as a bridge to lung transplantation. J Thorac Cardiovasc Surg 2013;145:1065-71.

51. Mangi AA, Mason DP, Yun JJ, et al. Bridge to lung transplantation using short-term ambulatory extracorporeal membrane oxygenation. J Thorac Cardiovasc Surg 2010;140:713-5.

52. Garcia JP, Iacono A, Kon ZN, et al. Ambulatory extracorporeal membrane oxygenation: a new approach for bridge-to-lung transplantation. J Thorac Cardiovasc Surg 2010;139:e137-9.

53. Garcia JP, Kon ZN, Evans C, et al. Ambulatory venovenous extracorporeal membrane oxygenation: innovation and pitfalls. J Thorac Cardiovasc Surg 2011;142:755-61.
54. Lindholm JA. Ambulatory veno-venous extracorporeal membrane oxygenation. J Thorac Dis 2018;10:S670-3.

55. Kotloff RM, Zuckerman JB. Lung transplantation for cystic fibrosis: special considerations. Chest 1996;109:787-98.

56. Chalermskulrat W, Sood N, Neuringer IP, et al. Non-tuberculous mycobacteria in end stage cystic fibrosis: implications for lung transplantation. Thorax 2006;61:507-13.

57. Cantón-Bulnes ML, Hurtado Martínez Á, López-Cerero $\mathrm{L}$, et al. A case of pan-resistant Burkholderia cepacia complex bacteremic pneumonia, after lung transplantation treated with a targeted combination therapy. Transpl Infect Dis 2019;21:e13034.

58. Daccò V, Claut L, Piconi S, et al. Successful ceftazidimeavibactam treatment of post-surgery Burkholderia multivorans genomovar II bacteremia and brain abscesses in a young lung transplanted woman with cystic fibrosis. Transpl Infect Dis 2019;21:e13082.

59. Aslam S, Courtwright AM, Koval C, et al. Early clinical experience of bacteriophage therapy in 3 lung transplant recipients. Am J Transplant 2019;19:2631-9.

60. Levitsky J, Doucette K, AST Infectious Diseases Community of Practice. Viral hepatitis in solid organ transplantation. Am J Transplant 2013;13 Suppl 4:147-68.

61. Buganza-Torio E, Doucette KE. Management of Viral Hepatitis in Solid Organ Transplant Recipients. Infect Dis Clin North Am 2018;32:635-50.

62. Olson MT, Triantafyllou T, Singhal S. Resumption of elective surgery during the COVID-19 pandemic: what lessons can we apply? Eur Surg 2020;1-3. [Epub ahead of print]. doi: 10.1007/s10353-020-00645-0.

63. Bharat A, Querrey M, Markov NS, et al. Lung transplantation for patients with severe COVID-19. Sci Transl Med 2020;12:eabe4282.

64. Ceulemans LJ, Van Slambrouck J, De Leyn P, et al. Successful double-lung transplantation from a donor previously infected with SARS-CoV-2. Lancet Respir Med 2021;9:315-8.

65. Castleberry AW, Martin JT, Osho AA, et al. Coronary revascularization in lung transplant recipients with concomitant coronary artery disease. Am J Transplant 2013;13:2978-88.

66. O'Rourke DJ, Quinton HB, Piper W, et al. Survival in patients with peripheral vascular disease after percutaneous coronary intervention and coronary artery bypass graft surgery. Ann Thorac Surg 2004;78:466-70; discussion 470.

67. Chang M, Lee CW, Ahn JM, et al. Predictors of longterm outcomes after bypass grafting versus drug- 
eluting stent implantation for left main or multivessel coronary artery disease. Catheter Cardiovasc Interv 2017;90:177-85.

68. Lee CW, Ahn JM, Cavalcante R, et al. Coronary Artery Bypass Surgery Versus Drug-Eluting Stent Implantation for Left Main or Multivessel Coronary Artery Disease: A Meta-Analysis of Individual Patient Data. JACC Cardiovasc Interv 2016;9:2481-9.

69. Makey IA, Sui JW, Huynh C, et al. Lung transplant patients with coronary artery disease rarely die of cardiac causes. Clin Transplant 2018;32:e13354.

70. Yerasi C, Roy SB, Olson M, et al. Outcomes of lung transplant recipients with preoperative atrial fibrillation. Asian Cardiovasc Thorac Ann 2018;26:127-32.

71. Vaquero Barrios JM, Redel Montero J, Santos Luna F. Comorbidities impacting on prognosis after lung transplant. Arch Bronconeumol 2014;50:25-33.

72. Hall EC, Pfeiffer RM, Segev DL, et al. Cumulative incidence of cancer after solid organ transplantation. Cancer 2013;119:2300-8.

73. Acuna SA. Etiology of increased cancer incidence after solid organ transplantation. Transplant Rev (Orlando) 2018;32:218-24.

74. Elnahas S, Olson MT, Kang P, et al. Factors associated with skin cancer in lung transplant recipients: A singlecenter experience. Clin Transplant 2019;33:e13718.

75. Weill D. Lung transplantation: indications and contraindications. J Thorac Dis 2018;10:4574-87.

76. Walia R, Omar A, Patel V, et al. Single center experience with prostate cancer in lung transplantation. Eur Respir J 2016;48.

77. Chambers DC, Cherikh WS, Goldfarb SB, et al. The International Thoracic Organ Transplant Registry of the International Society for Heart and Lung Transplantation: Thirty-fifth adult lung and heart-lung transplant report-2018; Focus theme: Multiorgan Transplantation. J Heart Lung Transplant 2018;37:1169-83.

78. Thabut G, Christie JD, Ravaud P, et al. Survival after bilateral versus single lung transplantation for patients with chronic obstructive pulmonary disease: a retrospective analysis of registry data. Lancet 2008;371:744-51.

79. Nathan SD, Shlobin OA, Ahmad S, et al. Comparison of wait times and mortality for idiopathic pulmonary fibrosis patients listed for single or bilateral lung transplantation. J Heart Lung Transplant 2010;29:1165-71.

80. Raghu G, Remy-Jardin M, Myers JL, et al. Diagnosis of
Idiopathic Pulmonary Fibrosis. An Official ATS/ERS/JRS/ ALAT Clinical Practice Guideline. Am J Respir Crit Care Med 2018;198:e44-68.

81. Idiopathic Pulmonary Fibrosis Clinical Research Network, Raghu G, Anstrom KJ, et al. Prednisone, azathioprine, and $\mathrm{N}$-acetylcysteine for pulmonary fibrosis. N Engl J Med 2012;366:1968-77.

82. King TE, Bradford WZ, Castro-Bernardini S, et al. A phase 3 trial of pirfenidone in patients with idiopathic pulmonary fibrosis. N Engl J Med 2014;370:2083-92.

83. Margaritopoulos GA, Trachalaki A, Wells AU, et al. Pirfenidone improves survival in IPF: results from a reallife study. BMC Pulm Med 2018;18:177.

84. Tzouvelekis A, Karampitsakos T, Ntolios P, et al. Longitudinal "Real-World" Outcomes of Pirfenidone in Idiopathic Pulmonary Fibrosis in Greece. Front Med (Lausanne) 2017;4:213.

85. Egan TM, Murray S, Bustami RT, et al. Development of the new lung allocation system in the United States. Am J Transplant 2006;6:1212-27.

86. Ferreira A, Garvey C, Connors GL, et al. Pulmonary rehabilitation in interstitial lung disease: benefits and predictors of response. Chest 2009;135:442-7.

87. Meyer DM, Edwards LB, Torres F, et al. Impact of recipient age and procedure type on survival after lung transplantation for pulmonary fibrosis. Ann Thorac Surg 2005;79:950-7; discussion 957-8.

88. Grossman RF, Frost A, Zamel N, et al. Results of singlelung transplantation for bilateral pulmonary fibrosis. The Toronto Lung Transplant Group. N Engl J Med 1990;322:727-33.

89. Neurohr C, Huppmann P, Thum D, et al. Potential functional and survival benefit of double over single lung transplantation for selected patients with idiopathic pulmonary fibrosis. Transpl Int 2010;23:887-96.

90. ten Klooster L, Nossent GD, Kwakkel-van Erp JM, et al. Ten-Year Survival in Patients with Idiopathic Pulmonary Fibrosis After Lung Transplantation. Lung 2015;193:919-26.

91. Wu H, Yu Y, Huang H, et al. Progressive Pulmonary Fibrosis Is Caused by Elevated Mechanical Tension on Alveolar Stem Cells. Cell 2020;180:107-121.e17.

92. Borie R, Kannengiesser C, Hirschi S, et al. Severe hematologic complications after lung transplantation in patients with telomerase complex mutations. J Heart Lung Transplant 2015;34:538-46.

93. Tokman S, Singer JP, Devine MS, et al. Clinical outcomes of lung transplant recipients with telomerase mutations. J 
Heart Lung Transplant 2015;34:1318-24.

94. Lahzami S, Bridevaux PO, Soccal PM, et al. Survival impact of lung transplantation for COPD. Eur Respir J 2010;36:74-80.

95. Levine SM, Anzueto A, Peters JI, et al. Medium term functional results of single-lung transplantation for endstage obstructive lung disease. Am J Respir Crit Care Med 1994;150:398-402.

96. Bavaria JE, Kotloff R, Palevsky H, et al. Bilateral versus single lung transplantation for chronic obstructive pulmonary disease. J Thorac Cardiovasc Surg 1997;113:520-7; discussion 528.

97. Pochettino A, Kotloff RM, Rosengard BR, et al. Bilateral versus single lung transplantation for chronic obstructive pulmonary disease: intermediate-term results. Ann Thorac Surg 2000;70:1813-8; discussion 1818-9.

98. Meyer DM, Bennett LE, Novick RJ, et al. Single vs bilateral, sequential lung transplantation for end-stage emphysema: influence of recipient age on survival and secondary end-points. J Heart Lung Transplant 2001;20:935-41.

99. Schaffer JM, Singh SK, Reitz BA, et al. Single- vs doublelung transplantation in patients with chronic obstructive pulmonary disease and idiopathic pulmonary fibrosis since the implementation of lung allocation based on medical need. JAMA 2015;313:936-48.

100. Ramos KJ, Smith PJ, McKone EF, et al. Lung transplant referral for individuals with cystic fibrosis: Cystic Fibrosis Foundation consensus guidelines. J Cyst Fibros 2019;18:321-33.

101.Paterson SL, Barry PJ, Horsley AR. Tezacaftor and ivacaftor for the treatment of cystic fibrosis. Expert Rev Respir Med 2020;14:15-30.

102.Middleton PG, Mall MA, Dřevínek P, et al. ElexacaftorTezacaftor-Ivacaftor for Cystic Fibrosis with a Single Phe508del Allele. N Engl J Med 2019;381:1809-19.

103.Keogh AM, Mayer E, Benza RL, et al. Interventional and surgical modalities of treatment in pulmonary hypertension. J Am Coll Cardiol 2009;54:S67-77.

104. Schaffer JM, Singh SK, Joyce DL, et al. Transplantation for idiopathic pulmonary arterial hypertension: improvement in the lung allocation score era. Circulation 2013;127:2503-13.

105. Kshettry VR, Kroshus TJ, Savik K, et al. Primary pulmonary hypertension as a risk factor for the development of obliterative bronchiolitis in lung allograft recipients. Chest 1996;110:704-9.
106. Verleden GM, Dupont L, Yserbyt J, et al. Recipient selection process and listing for lung transplantation. J Thorac Dis 2017;9:3372-84.

107. Bernstein EJ, Peterson ER, Sell JL, et al. Survival of adults with systemic sclerosis following lung transplantation: a nationwide cohort study. Arthritis Rheumatol 2015;67:1314-22.

108. Young LR, Hadjiliadis D, Davis RD, et al. Lung transplantation exacerbates gastroesophageal reflux disease. Chest 2003;124:1689-93.

109. Miele CH, Schwab K, Saggar R, et al. Lung Transplant Outcomes in Systemic Sclerosis with Significant Esophageal Dysfunction. A Comprehensive Single-Center Experience. Ann Am Thorac Soc 2016;13:793-802.

110. Shah N, Force SD, Mitchell PO, et al. Gastroesophageal reflux disease is associated with an increased rate of acute rejection in lung transplant allografts. Transplant Proc 2010;42:2702-6.

111.Patti MG, Vela MF, Odell DD, et al. The Intersection of GERD, Aspiration, and Lung Transplantation. J Laparoendosc Adv Surg Tech A 2016;26:501-5.

112.Arjuna A, Olson MT, Walia R, et al. An update on current treatment strategies for managing bronchiolitis obliterans syndrome after lung transplantation. Expert Rev Respir Med 2021;15:339-50.

113. Biswas Roy S, Elnahas S, Serrone R, et al. Early fundoplication is associated with slower decline in lung function after lung transplantation in patients with gastroesophageal reflux disease. J Thorac Cardiovasc Surg 2018;155:2762-2771.e1.

114. Hartwig MG, Anderson DJ, Onaitis MW, et al. Fundoplication after lung transplantation prevents the allograft dysfunction associated with reflux. Ann Thorac Surg 2011;92:462-8; discussion 468-9.

115. Gulack BC, Meza JM, Lin SS, et al. Reflux and allograft dysfunction: is there a connection? Thorac Surg Clin 2015;25:97-105.

116. Verleden GM, Vos R, Vanaudenaerde B, et al. Current views on chronic rejection after lung transplantation. Transpl Int 2015;28:1131-9.

Cite this article as: Arjuna A, Olson MT, Walia R. Current trends in candidate selection, contraindications, and indications for lung transplantation. J Thorac Dis 2021;13(11):6514-6527. doi: 10.21037/jtd-2021-09 